\section{FEATURE}

Catherine Barham

\section{Office for National Statistics}

\title{
Review of Labour Statistics for the United Nations Statistical Commission
}

\section{SUMMARY}

Early in 2007, the Office for National Statistics was asked by United Nations Statistics Division (UNSD) to carry out a Review of Labour Statistics on behalf of the UK. The Review was carried out during 2007 and was presented at the annual UN Statistics Commission session in February 2008 in New York. The Review was very well received and recommendations in the Review will be taken forward by UNSD and the International Labour Organisation. Specific recommendations relating to the faster adoption of international standards in labour statistics are due to be discussed at the International Conference of Labour Statisticians in November 2008.
1 the United Nations Statistical Commission (UNSC) meeting in New York at the end of February 2007, the UK (Office for National Statistics (ONS)) agreed to lead the 2008 Programme Review of Labour Market Statistics. ${ }^{1}$ The UNSC commission reviews on specific topics every year. Reviews carried out in previous years were:

- 2007: Review of Education Statistics - Statistics Canada

- 2006: Review of Industrial Statistics - Ministry of Internal Affairs and Communication, Japan

- 2005: Review of Energy Statistics - Statistics Norway

The primary objective of these Reviews is to provide a blueprint that can be taken forward by international agencies, national governments and other specialist agencies. In the case of the Review of Labour Statistics, this includes a focus on key issues to be followed up in the future in relation to labour statistics, given the different stages of economic development in countries across the world.

Although the commissioned project was initially a review of employment statistics, ONS decided at the outset to extend the scope to include the full range of labour market statistics. This enabled the work to cover the statistical implications of the current set of labour market statistics internationally now and in the future.

The Review was conducted using a combination of desk-based research and consultation with experts, alongside a survey of views of UN States Members. The key questions the Review addressed were:

- what is currently being done and who are the key players?

- how well is the current system working?

- is what is being done sufficiently in line with the demand for this type of statistics or are there gaps?

- what are the priority areas for the future?

Given the timescales and resources for this Review, the focus was on using secondary sources of evidence and to add value in terms of the collation and analysis of existing information and thinking conceptually about issues for the future. As the subject matter is very broad, it was important to involve international stakeholders at key stages throughout the process.

A range of international agencies is involved in labour statistics, including the Organisation for Economic Co-operation and Development (OECD), Eurostat, the International Monetary Fund (IMF), the United Nations Statistics Division (UNSD) and the World Bank. The role of the International Labour Organisation (ILO) is, however, key given its position as the specialised agency of the United Nations (UN) with specific responsibility for labour statistics, as detailed in the Memorandum of Understanding. It is for this reason that the ILO was consulted initially to discuss the scope of the Review, and throughout the whole process. 


\section{Review content}

As mentioned above, the objectives of the Review are kept deliberately broad by UNSD to enable the programme reviewers to decide on the pertinent issues. After a number of meetings with key stakeholders, three main broad areas were identified as being important in the Review. These were:

- successes and gaps in the current work of different organisations involved in labour statistics

- views and priorities of Member States of the UN, and

- extending the current labour market framework

Some detail of the Review findings is given on the main issues identified under these headings below.

\section{Successes and gaps in the current work of different organisations involved in labour statistics} Indicators of labour statistics A range of agencies produce indicators of labour statistics for countries internationally, but each with slightly different definitions, timescales, coverage and remits. A huge amount of progress has been made in harmonising concepts and definitions internationally, primarily through the work of the ILO. Promoting input harmonisation will continue to be a key part of collecting and disseminating comparable labour statistics in the future. Future work should focus on working closely with individual countries to encourage and promote the harmonisation of questions wherever possible. In addition, greater coherence would be achieved through developing a set of key labour statistics indicators common to the three main international agencies.

\section{Collation and dissemination activities}

The challenge in this section was summarising the successes of international agencies involved in collating and disseminating labour statistics. The aim here was to highlight some of these achievements which have a direct impact on the work of these agencies in the future. Research carried out as part of the Review indicated that although there is a wide range of information available internationally, there is some duplication. There are also a range of problems resulting from definitional differences, some of which can be addressed through adjusting conceptually consistent estimates.

In one sense, the main criterion for the compilation and dissemination of highquality labour statistics is that the statistics meet the needs of the individuals and organisations using them. This is, however, a difficult area on which to get a consensus. It was decided for this reason that the best method would be to carry out a survey of National Statistics Institutes and ask specific questions relating to the process of providing data to International Agencies and how this could be improved. Some of the findings from this questionnaire are presented in the later section on views and priorities of Member States.

The main aims behind collecting and disseminating labour market statistics for all three organisations are similar. These include comparisons between countries, ensuring the statistics are relevant and reliable, and assessing whether the aims of the specific organisation are being achieved. Each organisation has, however, its own focus and as a consequence has slightly different interests. Eurostat will be interested in different issues from lower-income countries, which may fall more under the focus of ILO. The ILO has been working to improve the quality of the labour statistics they collect and disseminate. In the latest (5th) edition of Key Indicators of the Labour Market (KILM), there have been various enhancements, including improvements to some of the indicators which make it easier to compare across countries. There have also been improvements in the geographic coverage and timeliness of information due to changes in the collection and processing of the information.

One of the biggest issues facing the ILO in terms of its data compilation and dissemination activities is non-response from countries. In 2006, the annual questionnaire for the Yearbook was sent to 232 countries but only around 20 per cent responded in full, though approximately 50 per cent gave partial responses. This clearly impacts on the ability of the ILO to make assessments about the quality of labour statistics in the countries unable to respond. There are additional problems associated with the fact that some countries are unable to provide the information in the format or for the time periods required. A key part of collecting and disseminating high-quality information on labour statistics is the ability to provide accurate metadata on sources and methods of collection. Research for the Review has found that in some instances this is limited or insufficient. This restricts the extent to which comparisons can be made internationally. In order to address this issue, it was recommended that international agencies should also look into ways of sharing best practice as regards collecting labour statistics, to enable comparisons to be made internationally. This would include using the concept of capturing data once and using many times, which would speed up the data collection process and reduce the burden for member countries.

\section{Development work by international agencies}

This section looked briefly at some of the development work carried out by the main international agencies involved in labour statistics. One of the major conceptual developments in the ILO has been the common goals encapsulated in the Decent Work Agenda. This concept was introduced in 1999 and provides a framework for the integration and development of statistics both within and outside the ILO. It is defined as 'productive work in conditions of freedom, equity, security and human dignity'. One of the difficulties is that applying the concept of decency to economic activity is open to interpretation. However, as the KILM collects a broad range of labour market indicators, it is useful for assessing many of the issues relating to the Decent Work Agenda.

The ILO is also responsible for the development of international standards for the measurement of labour statistics and for their enhanced international comparability. The continuation of this work is vital in order to provide the framework around which harmonised labour statistics can be produced. This Review has, however, highlighted the need to speed up the process by which standards are discussed, developed and agreed. This could involve the development of expert groups, to work on topical issues.

The OECD has various enhancements to labour market statistics planned for 2007-08. One of these is to provide more background information on the comparability of headline labour series, and reasons for differences between labour force data and estimates compiled by national accountants is envisaged. Another improvement is to request a small number of countries slow at responding to the annual questionnaire to speed up their response.

Eurostat's current activities on improving the quality of labour market statistics include: quality assurance of the LFS; consistency with national accounts; 
developing annual LFS ad hoc modules that address specific aspects or interactions of the labour market with other domains; implementation of quarterly job vacancy statistics; creation of a European socialeconomic classification and implementation of the NACE Rev. 2 activity classification; and the definition of a system of Quality of Employment indicators.

\section{Technical assistance}

A relatively large part of the ILO's responsibility in the arena of international labour statistics can be grouped under the heading of providing technical assistance to member countries. The ILO's standard setting and technical co-operation activities are reinforced by an extensive research, training, education and publications programme. As part of this, the ILO runs the International Training Centre in Turin, the aim of which is to provide training in subjects that further the ILO's pursuit of decent work for all. In addition to running training courses, the centre also acts as a meeting place and runs distance learning courses. The centre runs more than 350 courses per year for a total of around 8,000 people. These include courses on labour statistics, labour market information systems and labour market analysis.

This sort of training can be seen as an integral part of the statistical capacitybuilding agenda. A recent external audit of ILO activities relating to the production of statistics highlighted the need for more professional staff in both its headquarters and regional offices. This is in order to provide additional technical assistance to countries. In addition, it recommended that each regional office should have at least one professional staff person specialised in standards and methods for survey design and data collection.

Views and priorities of Member States of the United Nations It was decided relatively early on in the Review that the only way of getting a consensus on the main issues regarding the role of international agencies involved in labour statistics was to carry out a survey of UN member countries. It was decided that this could also be used to get some idea of the main issues facing countries in the future. In addition to these specific questions, the questionnaire included a suite of questions which were used to create a breakdown of responding countries by the presence or absence of a regular labour force survey. These questions were based on ILO work which looked at the characteristics of systems of labour statistics in countries at different stages of statistical development. Looking at response rates using these categories indicates that of the 69 responding countries:

- 56 per cent had regular and reliable LFSs on a monthly or quarterly basis along with high-quality business statistics

- 21 per cent had labour statistics from an ad hoc LFS and some business statistics, and

- 23 per cent had no LFS or business statistics at all

One of the major issues with analysing results such as these from a self-completion questionnaire is differential response rates for economies at different levels of development. The overall response rate was 36 per cent and responses were significantly higher in high-income OECD countries compared with low and lower middleincome countries. Interestingly, the group with the second-lowest response rates was the high-income non-OECD countries.

The questionnaire also included questions which enabled countries to be classified according to their development level (high income/middle income/low income). This meant that some of the findings could be looked at in terms of the spread across groups of countries at similar levels of development. Figure 1 gives an illustration of this.

Figure 1

What do you see as the main role of international agencies? Percentages

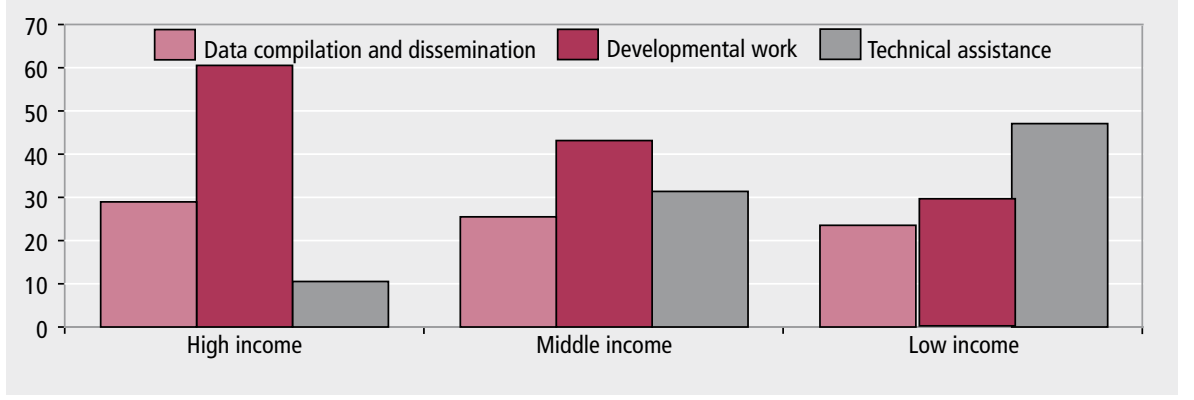

Extending the current labour market framework

In the majority of developed countries, a large amount of labour market data is available. Despite this, researchers, statisticians and politicians have encountered major problems in obtaining a complete picture of the labour market. The main reasons for this include:

- incomplete coverage

- contradictory results between data sources

- difficulties and limitations in describing labour market dynamics

- the absence of links between labour market statistics and other social and economic statistics

In the early 1980s, an international discussion took place on how to overcome these difficulties. The proposed solution was an integral framework of labour accounts, or labour accounting system (LAS) which acquired a wide international acceptance, including the ILO and European Commission (which in 2003 published the Handbook on Social Accounting Matrices and Labour Accounts). The main aim of the LAS in this context was to combine statistical data sources to enhance their strength and overcome their weaknesses in order to produce new series of superior quality to the original data. The main advantages in compiling an LAS include the guaranteed links with national accounts and demographic data, the elimination of contradictory results and an output which gives a global overview of the labour market (especially in terms of improving consistency of inputs and outputs in productivity).

In the UK, a conceptual framework for a labour accounting system was developed by ONS in 2002 as part of a quality review of labour statistics. This framework is based on a set of four main organising principles: concepts and definitions underpinning the statistics; sources and methodology for the derivation of the data; arrangements for presenting and disseminating the data; and links with other statistics. The framework has at its core well-established international recommendations, for example those presented by the ILO, embracing also the need for comprehensive coverage of the statistics. These various features incorporate, to a greater or lesser extent, certain principle of economic behaviour which underpin the inter-relationships of the variables, in particular the demand/ supply structure. 
In the UK at present, the framework for labour market statistics is largely implicit within the existing form of presentation, and the monthly First Release data are provided from a range of sources describing all the main elements of the labour market. The fact that the main concepts mainly follow recognised and well-established international standards is strength of the framework. The aim of such a framework nationally is primarily to produce a set of guiding principals which help understand the process of collection, production, dissemination and analysis of information on the various aspects of labour markets. Applying such a framework internationally has improved consistency and comparability of the range of sources.

The framework as it stands at present has four main units of measurement. These are people (in terms of their employment status), posts (jobs or vacancies), money (pay) and time (hours worked), and a variety of classificatory schema (such as occupation and job search activities). There are, however, a number of shortfalls with the existing system as outlined below.

Further development of dynamic aspects

The system as it stands is a static system which relies mainly on point-in-time estimates of factors on both supply and demand sides. This, to a certain extent, reflects the cross-sectional data on which the framework is based from both survey and administrative sources. These snapshots do not present a complete picture of the labour market as they lack information on the underlying movements in and out of unemployment, employment and inactivity which result in the observed structure of the labour force.

Systems of labour statistics have not, traditionally, been orientated towards these significant labour market events, but more towards their overall effect on stock levels of employment and unemployment. A shift towards collecting and disseminating information on gross flows would greatly enhance the overall picture of labour markets nationally. In addition, the importance of dynamics in capturing the variety of transitions within the labour market has been identified as an issue for the future by a Eurostat task force. ${ }^{1}$ Interestingly enough, many of the labour force surveys already in existence could be adapted relatively easily to collecting information on labour dynamics. The rotating panel design of the majority of labour force surveys make it possible to link together information on the same individuals over a number of points in time.

More generally, information on flows could also be used in the measurement of labour underutilisation. In the past, attachment to the labour market has been measured on the basis of the criteria for defining unemployment and the reasons for seeking work or for not being available for work. In the context of labour underutilisation, it may be more analytically relevant to define people who are marginally attached to the labour market in terms of the propensity of economically inactive persons to become economically active. In addition, collecting information on the barriers faced by those not in the labour force to becoming active would enable the group who are inactive involuntarily to be identified.

In the UK, there has been a focus in recent years on collecting and analysing better information about people who are marginally attached to the labour force. This has included extending labour force survey questions to determine people's propensity to work in the future, and using flows data to look at movement into and out of inactivity for certain groups of people. Using this sort of information to supplement headline figures on economic activity on a national basis should be encouraged in order to develop a more complete understanding of the characteristics of labour markets.

\section{Parallel framework for labour demand}

The labour market framework as it stands concentrates mainly on the labour supply elements of the system. These factors are mainly measured through labour force surveys and include the characteristics of people, the type of characteristics of their jobs, and the families and households in which they live. The demand side of the framework tends to be measured through a range of administrative sources, supplemented with information from a range of employers and business surveys. The link between the supply and demand elements of the labour market has, over time, become increasingly important as understanding the differences between inputs and outputs has become a higher priority issue in many countries, particularly in the developed world. Reconciling the business and employers surveys on topics such as vacancies and number and type of jobs is vital in understanding the process of individuals taking up particular jobs. Across the world, a key aspect of a labour statistics system is understanding the match between jobs and skill levels of employers in order to achieve maximum productivity.

Integrating the demand side of the existing labour market framework into this model provides a number of new challenges. These can be considered in terms of a greater understanding of how jobs are created and lost and the relationship between jobs and posts. From the point of view of the needs of employers, the process of feeding this kind of information via governments to the health and education systems will serve to complete the circle through improving service provision to meet the needs of employees and ultimately employers.

\section{Extending the use of family and household labour statistics}

Demographers generally identify a number of key trends in family formation and structure that have taken place in Europe during the latter part of the 20th century. These include: delaying the transition to parenthood with childbearing being compressed in a small number of years at a later age; declining fertility rates resulting in smaller family size; the separation of marriage and parenting; and growing numbers living alone. The result of these changes mean the family in much of the western world has evolved from a fairly standardised model of marriage and children, often including living with older generations, to becoming a much more varied model of smaller family size, less tied by institutional definitions.

Elements of these trends can be identified in many countries across the world, and although these changes have been measured in relation to the size and structure of the population, their impact on the changing nature of work is still relatively unclear. The framework as it stands at present indicates a link between families and households and people, in terms of type and composition, but this needs expanding to cover the changing nature of families and work. The relationship between unpaid family work and paid employment, particularly for women, is essential to understanding the matching of jobs with people.

In addition, it would be hugely beneficial to employ the type of modelling used in measuring consumption at the household level to look at including unpaid work in the family and wider community, as well as some of the less clearly defined boundaries between work and family life. Extending the range of information collected at a household level to include a measurement of time spent on various unpaid activities, 
the money transfers or transfers in kind which occur between the households or with other households, and how decisions on education and health are negotiated within the household, could provide a more useful framework for collecting, understanding and using labour statistics.

\section{Developing the interactions with other areas}

A further criticism of the current framework is that it fails to integrate some of the interactions with other domains. Areas which have an impact on elements of the labour market include health, education, national accounts and population and demography. Some of these overlaps are implicit in the way labour market information is presented, for example, presenting employment/ unemployment and inactivity rates by demographic characteristics including age, gender and ethnic group. In these cases, the information tends to come from the same source and is therefore easier to integrate in this way. Other areas are more complex to integrate due to issues arising as a result of different sources, concepts and definitions.

In an increasingly complex world, looking at the labour statistics system in isolation would seem to be restrictive in terms of being able to understand the processes behind the headline figures. Using the framework as a starting point, individual countries should be encouraged to look at the labour market as being part of a wider statistical system and consequently investigating some of the interactions between domains. This will then raise awareness of the extent of comparability of different sources of information.

\section{Recommendations from the Review}

Clearly the field of international labour statistics is broad and varied, and the Review focused on the areas where specific improvements can be made in the future.

While the Review recognised the impressive coverage and diversity of information on various aspects of labour markets, it pointed to the need for greater coordination to improve the quality and coherence of these statistics. It also highlighted the need for greater responsiveness to address topical issues for the future.

While numerous other issues were identified and suggestions made in the body of the report, the following recommendations were given top priority:
- the ILO should prioritise the activities required to improve the harmonisation of concepts and methods which support the production, transmission and dissemination of comparable labour statistics; should produce an action plan; and should then coordinate the implementation of this plan

- the ILO should develop a coordinated system for providing technical assistance to help countries to provide high-quality labour statistics

- the ILO should work with UNSD, OECD and Eurostat to improve the process of setting international standards by, for example:

- reviewing the frequency, duration and agenda-setting of ICLS meetings - extending the use of expert groups to work on topical issues

- the ILO should establish and coordinate a series of working groups to discuss each of the five topics identified for development work in this Review. In some instances this may involve working with groups already in existence:

- changing structure of the labour force

- informal employment and the non-observed economy

- child and forced labour

- measurement of productivity

- globalisation

- the ILO should coordinate work to improve the consistency and relevance of outputs by developing an updated version of the labour statistics framework which places greater emphasis on:

- dynamic elements, that is, information on flows

- the need to integrate and reconcile measures of labour demand with labour supply

- integrating family and household information

- integrating with other statistics/ policy domains

\section{Presentation of the Review to UNSD}

The Review was presented to the UNSC at the annual meeting in New York in February 2008. It received a very positive reception from UN member countries, and the ILO, who noted their appreciation of the work involved. The report of this session is included below.

The Statistical Commission:

- commended the high-quality programme review report on labour statistics prepared by the UK, took note of the recommendations therein, and welcomed the constructive response and comments made by the ILO

- emphasised the need for better coordination to improve the quality and coherence of labour statistics at the national and global levels, which should be done in consultation with the Committee for the Coordination of Statistical Activities

- reiterated the importance of methodological developments, including the harmonisation of conceptual frameworks, related definitions and possible assessments and updating of the labour accounting framework, emphasised that this work was to be driven by the existing expert and working groups, and also reiterated that broad country representation, including from developing countries, should be ensured

- considered that full implementation of the recommendations of the programme review could overburden the ILO, given existing resources, emphasised the need for prioiritisation of those recommendations, and requested the development of a road map for their implementation

- asked the donor community to support international technical assistance to enhance the capability of developing countries to produce high-quality labour statistics, and noted that technical assistance should be coordinated and implemented within existing technical cooperation programmes, and

- welcomed the work done by the ILO ICLS and suggested that it might wish to review its methods of operation, in particular the frequency and duration of its sessions, and urged the members states to attend the forthcoming conference

\section{Relevance for ONS/LMD further work}

Within LMD there are a number of ongoing pieces of work which are consistent with these recommendations and therefore improve the UK's contribution to international priority areas:

- the LMD analysis team is looking into improving the published information on longitudinal flows between economic activity states in order to gain a greater understanding of the gross flows which contribute to the net 
headline figures

- the analysis team will continue to develop and improve the household and family information published from the household LFS and APS

- some initial work is being carried out looking at the feasibility of developing a conceptual framework for labour market statistics, and at social statistics frameworks more generally

\section{Notes}

1 The full Review is available on the UN Statistics Commission website at http://unstats.un.org/unsd/statcom/ sc2008.htm

\section{CONTACT}

凶elmr@ons.gsi.gov.uk 